\title{
Cause-specific mortality in Scottish patients with colorectal cancer with and without type 2 diabetes (2000-2007)
}

\author{
J. J. Walker • D. H. Brewster • H. M. Colhoun • \\ C. M. Fischbacher • R. S. Lindsay $\cdot$ S. H. Wild \\ on behalf of the Scottish Diabetes Research Network (SDRN) Epidemiology Group
}

Received: 26 November 2012 / Accepted: 5 April 2013 / Published online: 27 April 2013

(C) Springer-Verlag Berlin Heidelberg 2013

\begin{abstract}
Aims/hypothesis The objective of this study was to use Scottish national data to assess the influence of type 2 diabetes on (1) survival (overall and cause-specific) in multiple time intervals after diagnosis of colorectal cancer and (2) cause of death.

Methods Data from the Scottish Cancer Registry were linked to data from a population-based national diabetes register. All people in Scotland diagnosed with non-
\end{abstract}

Members of the SDRN Epidemiology Group beyond the authors listed: I. Brady, University of Dundee; J. Chalmers, Victoria Hospital, Kirkcaldy; S. Cunningham, University of Dundee; A. EmslieSmith, Arthurstone Medical Centre, Dundee; L. Govan, University of Glasgow; B. Guthrie, University of Dundee; G. Leese, University of Dundee; D. Levin, University of Dundee; S. Livingstone, University of Dundee; H. Looker, University of Dundee; R. McAlpine, Diabetes Managed Clinical Network, NHS Tayside; J. McKnight, Western General Hospital, Edinburgh; A. Morris, University of Dundee; D. Pearson, Aberdeen Royal Infirmary, Aberdeen; J. Petrie, University of Glasgow; S. Philip, Grampian Diabetes Research Unit, Aberdeen; N. Sattar, University of Glasgow.

Electronic supplementary material The online version of this article (doi:10.1007/s00125-013-2917-x) contains peer-reviewed but unedited supplementary material, which is available to authorised users.

J. J. Walker $(\bowtie) \cdot$ S. H. Wild

Centre for Population Health Sciences,

The University of Edinburgh, Teviot Place,

Edinburgh EH8 9AG Scotland, UK

e-mail: jeremy.walker@ed.ac.uk

D. H. Brewster $\cdot$ C. M. Fischbacher

Information Services Division, NHS National Services Scotland,

Edinburgh, UK

H. M. Colhoun

Biomedical Research Institute, University of Dundee, Dundee, UK

R. S. Lindsay

British Heart Foundation Glasgow Cardiovascular Research

Centre, University of Glasgow, Glasgow, UK metastatic cancer of the colon or rectum in 2000-2007 were included. The effect of pre-existing type 2 diabetes on survival over four discrete time intervals $(<1,1-2,3-5$ and $>5$ years) after cancer diagnosis was assessed by Cox regression. Cumulative incidence functions were calculated representing the respective probabilities of death from the competing causes of colorectal cancer, cardiovascular disease, other cancers and any other cause.

Results Data were available for 19,505 people with colon or rectal cancer (1,957 with pre-existing diabetes). Causespecific mortality analyses identified a stronger association between diabetes and cardiovascular disease mortality than that between diabetes and cancer mortality. Beyond 5 years after colon cancer diagnosis, diabetes was associated with a detrimental effect on all-cause mortality after adjustment for age, socioeconomic status and cancer stage (HR [95\% CI]: $1.57[1.19,2.06]$ in men; 1.84 [1.36, 2.50] in women). For patients with rectal cancer, diabetes was not associated with differential survival in any time interval.

Conclusions/interpretation Poorer survival observed for colon cancer associated with type 2 diabetes in Scotland may be explained by higher mortality from causes other than cancer.

Keywords Cardiovascular disease - Colorectal cancer . Survival analysis

$\begin{array}{ll}\text { Abbreviations } \\ \text { CIF } & \begin{array}{l}\text { Cumulative incidence function } \\ \text { CRC }\end{array} \\ \text { Colorectal cancer } \\ \text { CVD } & \text { Cardiovascular disease } \\ \text { ICD } & \text { International Classification of Diseases } \\ \text { NSS } & \text { National Services Scotland } \\ \text { SCI-DC } & \begin{array}{l}\text { Scottish Care Information-Diabetes } \\ \end{array} \\ \text { Collaboration } \\ \text { SES } & \text { Socioeconomic status } \\ \text { SIMD } & \text { Scottish Index of Multiple Deprivation }\end{array}$




\section{Introduction}

Diabetes mellitus is a common chronic disease associated with increased incidence of cancer at various sites (including colon and rectum) compared with general or nondiabetic populations [1-4]. Pre-existing diabetes at cancer diagnosis is also associated with poorer overall survival in patients with colorectal cancer (CRC) [5-13]. However, investigation of cause-specific mortality in this context has been limited, and findings have been mixed. Three studies report a relationship between diabetes and increased CRC mortality [11-13], although, in one of these [13], increased CRC mortality was observed in people with diabetes who were diagnosed with rectal cancer but not in those with colon cancer. Two further investigations found no significant effect of diabetes on CRC-specific mortality [8, 10]. The mixed evidence for an effect of diabetes on death specifically from CRC suggests that the observed poorer overall survival may reflect an increased hazard of death from other causes. Diabetes is associated with increased mortality from cardiovascular disease (CVD) in many populations, but only one previous study [12] appears to have investigated associations between pre-existing diabetes and survival after CRC when death from CVD is defined as the endpoint. This study reported a significant relationship between pre-existing type 2 diabetes mellitus and higher CVD mortality. A recent review evaluating the impact of diabetes on mortality in patients with cancer [14] identified the potential for death from competing causes as one of nine key points on the pathway from cancer to death at which the influence of diabetes may be obscured by confounding. This review recommended that studies assessing the influence of diabetes on long-term mortality should capture deaths from causes other than cancer, and perform competing risk survival analyses. The study reported here conforms with these recommendations. The main objective was to investigate whether pre-existing type 2 diabetes in patients with cancer of the colon or rectum was associated with the probability of death from four general causes (CRC itself, CVD, other cancers, and any remaining cause), while recognising the mutually exclusive nature of these competing mortality risks. A second objective was to assess whether preexisting type 2 diabetes in people diagnosed with cancer of the colon or rectum was associated with altered overall survival (relative to that of individuals without diabetes) in a number of discrete time intervals after cancer was detected.

\section{Methods}

Data sources Data for all people diagnosed with either cancer of the colon (International Classification of Diseases-Tenth Revision [ICD10; www.who.int/ classifications/icd/en/] codes $\mathrm{C} 18$ and $\mathrm{C} 19)$ or rectal cancer (ICD10 code C20) in Scotland during 2000-2007 were provided by the Scottish Cancer Registry [15]. Although dictated largely by the availability of data, this period is analytically convenient in that it broadly pre-dates the introduction of national bowel cancer screening in Scotland (implemented from June 2007 onwards), which could (by earlier detection of CRC) potentially affect survival. For each individual, data were limited to the chronologically earliest tumour: the date of cancer diagnosis for a person with multiple tumours at the affected site (colon or rectum) was that on which the first tumour was observed. Patients were followed-up until the earlier of date of death or 31 December 2010. Information on cancer treatment was provided by three dichotomous indicators marking receipt of surgery, radiotherapy or chemotherapy. The socioeconomic status (SES) of patients was represented by the Scottish Index of Multiple Deprivation (SIMD). This is a smallarea-based measure which combines 31 individual indicators across seven conceptual domains: income, employment, health, education, housing, geographic access and crime [16]. For the purposes of this study, SIMD scores were expressed as quintiles, the first and fifth quintiles corresponding to the least and most deprived groups in the population, respectively. Diabetes status was identified using a 2008 extract of the Scottish Care InformationDiabetes Collaboration (SCI-DC) dataset [17]. This resource has developed over time and, by 2007, held clinical and demographic data on more than $99 \%$ of patients with diabetes in Scotland. Data from SCI-DC were linked to the cancer registration records by the Information Services Division of NHS National Services Scotland (NSS). The linked dataset served to classify patients with CRC according to whether they did or did not have comorbid type 2 diabetes when cancer was detected. Cancer registration records were linked to death certificate information held by National Records of Scotland. Scottish death records make provision for a primary ('underlying') cause of death and for up to ten secondary causes, with coding based on ICD rules for identifying underlying cause of death from conditions recorded on the death certificate [18]. In practice, where both cancer and CVD are mentioned in part I of the death certificate, then the condition mentioned first will be identified as the underlying cause of death. Approval to create the pseudonymised linked research database was obtained from the Scottish multicentre research ethics committee, Caldicott Guardians of all Health Boards in Scotland, and the Privacy Advisory Committee of NSS.

Statistical analysis For each cancer site, a Cox regression model was fitted in which survival time was initially predicted by age at cancer diagnosis, and by the presence/absence of pre-existing type 2 diabetes. A separate 
model was fitted for each sex. This stratification by sex was motivated by the higher prevalence of diabetes and CVD in men, and by higher CRC incidence in men than in women. The initial model was successively refitted with the incremental inclusion of additional predictors: SES (SIMD quintile); cancer stage at diagnosis; and the cancer treatment markers. For colon cancer, the latter were restricted to indicators representing receipt of surgery and chemotherapy, because radiotherapy is little used in the management of primary colon cancer. For rectal cancer, markers for all three treatment regimens were admitted to the model. The models that featured the treatment markers included both main effects and two-way interactions (e.g. surgery with chemotherapy), to represent the effects of treatment combinations. Information on stage at diagnosis (Dukes' system, stages A to D) was missing for $19.0 \%$ of men (20.1\% of women) with colon cancer, and for $25.8 \%$ of men (31.8\% of women) with cancer of the rectum. These patients were excluded from all analyses. Addition of the treatment indicators was only possible for a subgroup, because these markers were not available for all patients. In all models, the binary indicator of diabetes status yielded an estimate of the HR associated with comorbid type 2 diabetes. Patients with diabetes diagnosed subsequent to cancer during the follow-up period were excluded from analysis. This applied to 209 of 1,086 men $(19.2 \%)$ with colon cancer and type 2 diabetes, 89 of 385 men (23.1\%) with rectal cancer and type 2 diabetes, 124 of 774 women $(16.0 \%)$ with colon cancer and type 2 diabetes, and 36 of 170 women $(21.2 \%)$ with rectal cancer and type 2 diabetes. Patients with type 1 diabetes that preceded cancer were also excluded from analysis. The validity of the proportional hazards assumption was checked by adding to each initial model (i.e. that adjusted for age only) a term representing the interaction of diabetes status with time. For the colon cancer models, this returned $p=0.004$ for men and $p<0.001$ for women, indicating that the assumption of proportional hazards for the effect of diabetes was questionable for both sexes. To reflect the non-constant effect of preexisting diabetes over time, interaction terms were defined to represent the effect of type 2 diabetes in the following discrete time periods after diagnosis with cancer: $0-1$ year; $>1-2$ years; $>2-5$ years; and beyond 5 years. Models were successively refitted with each period defined as the reference interval, permitting the main effect of diabetes within that period after cancer diagnosis to be investigated. The assumption of proportional hazards was not violated for the rectal cancer models, the interaction of diabetes with survival time returning $p=0.290$ for men and $p=0.874$ for women. However, in the interests of applying a common analytical approach, the method described for colon cancer was also used for the rectal cancer analyses. For both sites, visual inspection of $\log (-\log [$ survival] $)$ plots confirmed that the proportional hazard assumption was reasonable within each time window. Modelling was performed using the PHREG procedure in SAS (Version 9.3; SAS Institute Inc., Cary, NC, USA). Patients with metastatic disease (Dukes' stage D) were included in the main analysis, and a sensitivity analysis was conducted by refitting all models after exclusion of patients with metastatic cancer at diagnosis.

To provide insight into how the influence of type 2 diabetes on cause of death behaved over time, cumulative incidence functions (CIFs) [19, 20] were generated to represent the respective probabilities of death from CRC, CVD, any other cancer, and all other causes combined. Cause of death was established solely from the primary cause recorded in death certificates. Following the approach taken by an earlier study [13], the CRC mortality outcome included deaths from either colon or rectal cancer. Defining CRC mortality in this way was intended to offset any effects of misclassification of cause of death (i.e. rectal cancer being recorded as the underlying cause in people dying from colon cancer and vice versa). CVD deaths comprised those in which the primary cause of death was ischaemic heart disease (ICD10 codes I20 to I25, I46) or cerebrovascular disease (ICD10 codes I60 to I69). For each cause of death, equivalence of CIFs between those with and without diabetes was assessed using the test devised by Gray [21], which evaluates the null hypothesis that CIFs for a specific event type are identical across multiple groups. All analyses relating to CIFs were performed using the R software package 'cmprsk'.

\section{Results}

Table 1 presents survival status, demographic and clinical characteristics for people with colon cancer, by diabetes status. In men with colon cancer who died during the follow-up period, CRC was the dominant cause of death and other cancers the second most common cause in both groups. In women with colon cancer, other cancers was the second most common cause of death in those without diabetes, while CVD was the second most common cause of death in the diabetes group. For both sexes, the proportions of deaths from CVD were appreciably higher in those with pre-existing diabetes than in those with no diabetes. People with pre-existing type 2 diabetes were more deprived, and older when cancer was diagnosed, than those without diabetes. For men, cancer stage at diagnosis was very similar regardless of diabetes status; women with type 2 diabetes were less likely to have metastatic disease at diagnosis than women without diabetes. Differences in cancer treatment were also evident: for both sexes, those with type 2 diabetes were less likely to have received chemotherapy. 
Table 1 Characteristics of people with colon cancer included in study, by sex and diabetes status

\begin{tabular}{|c|c|c|c|}
\hline Characteristic & $\begin{array}{l}\text { No T2DM at diagnosis } \\
\text { of colon cancer }\end{array}$ & $\begin{array}{l}\text { T2DM at diagnosis } \\
\text { of colon cancer }\end{array}$ & $p$ value $^{\mathrm{a}}$ \\
\hline \multicolumn{4}{|l|}{ Men } \\
\hline Patients/deaths & $6,597 / 4,036$ & $877 / 579$ & \\
\hline \multicolumn{4}{|l|}{ Survival status at study end $(n / \%$ of total $)$} \\
\hline $\begin{array}{l}\text { Still alive } \\
\text { Dead, colon cancer }\end{array}$ & $\begin{array}{l}2,561 / 38.8 \\
2,464 / 37.4\end{array}$ & $\begin{array}{l}298 / 34.0 \\
324 / 36.9\end{array}$ & \\
\hline Dead, rectal cancer & $124 / 1.9$ & $17 / 1.9$ & $<0.001$ \\
\hline Dead, CVD & $352 / 5.3$ & $80 / 9.1$ & \\
\hline Dead, other cancers & $639 / 9.7$ & $85 / 9.7$ & \\
\hline Dead, other causes & $457 / 6.9$ & $73 / 8.3$ & \\
\hline \multicolumn{4}{|l|}{ SIMD quintile ( $n / \%$ of total) } \\
\hline $\begin{array}{l}\text { Q1 (least deprived) } \\
\text { Q2 }\end{array}$ & $\begin{array}{l}1,305 / 19.8 \\
1,360 / 20.6\end{array}$ & $\begin{array}{l}140 / 16.0 \\
158 / 18.0\end{array}$ & \\
\hline Q3 & $1,394 / 21.1$ & $188 / 21.4$ & $<0.001$ \\
\hline $\begin{array}{l}\text { Q4 } \\
\text { Q5 (most deprived) }\end{array}$ & $\begin{array}{l}1,376 / 20.9 \\
1,162 / 17.6\end{array}$ & $\begin{array}{l}181 / 20.6 \\
210 / 24.0\end{array}$ & \\
\hline Age at diagnosis, years (mean (SD)) & $69.5(11.4)$ & $71.4(8.7)$ & $<0.001$ \\
\hline Follow-up time, years (median (interquartile range) $)^{\mathrm{b}}$ & $3.2(5.1)$ & $3.0(4.5)$ & 0.004 \\
\hline \multicolumn{4}{|l|}{ Dukes' stage at diagnosis $(n / \%$ of total) } \\
\hline Stage A & $694 / 10.5$ & $94 / 10.7$ & \\
\hline Stage B & $2,205 / 33.4$ & $298 / 34.0$ & 0.979 \\
\hline $\begin{array}{l}\text { Stage C } \\
\text { Stage D }\end{array}$ & $\begin{array}{l}1,962 / 29.7 \\
1,736 / 26.3\end{array}$ & $\begin{array}{l}256 / 29.2 \\
229 / 26.1\end{array}$ & \\
\hline \multicolumn{4}{|l|}{ Surgery $(n / \%$ of total $)$} \\
\hline No & $811 / 12.3$ & $121 / 13.8$ & \\
\hline Yes & $5,742 / 87.0$ & $752 / 85.8$ & 0.211 \\
\hline Unknown/missing & $44 / 0.7$ & $4 / 0.5$ & \\
\hline \multicolumn{4}{|l|}{ Chemotherapy ( $n / \%$ of total) } \\
\hline No & $4,061 / 61.6$ & $601 / 68.5$ & \\
\hline Yes & $2,232 / 33.8$ & $227 / 25.9$ & $<0.001$ \\
\hline Unknown/missing & $304 / 4.6$ & $49 / 5.6$ & \\
\hline \multicolumn{4}{|l|}{ Women } \\
\hline Patients/deaths & $6,574 / 3,874$ & $650 / 426$ & \\
\hline \multicolumn{4}{|l|}{ Survival status at study end ( $n / \%$ of total) } \\
\hline $\begin{array}{l}\text { Still alive } \\
\text { Dead, colon cancer }\end{array}$ & $\begin{array}{l}2,700 / 41.1 \\
2,409 / 36.6\end{array}$ & $\begin{array}{l}224 / 34.5 \\
240 / 36.9\end{array}$ & \\
\hline Dead, rectal cancer & $100 / 1.5$ & $7 / 1.1$ & $<0.001$ \\
\hline $\begin{array}{l}\text { Dead, CVD } \\
\text { Dead, other cancers }\end{array}$ & $\begin{array}{l}293 / 4.5 \\
595 / 9.1\end{array}$ & $\begin{array}{l}64 / 9.9 \\
54 / 8.3\end{array}$ & \\
\hline Dead, other causes & $477 / 7.3$ & $61 / 9.4$ & \\
\hline \multicolumn{4}{|l|}{ SIMD quintile $(n / \%$ of total) } \\
\hline $\begin{array}{l}\text { Q1 (least deprived) } \\
\text { Q2 }\end{array}$ & $\begin{array}{l}1,258 / 19.1 \\
1,342 / 20.4\end{array}$ & $\begin{array}{l}84 / 12.9 \\
124 / 19.1\end{array}$ & \\
\hline Q3 & $1,457 / 22.2$ & $127 / 19.5$ & $<0.001$ \\
\hline $\begin{array}{l}\text { Q4 } \\
\text { Q5 (most deprived) }\end{array}$ & $\begin{array}{l}1,386 / 21.1 \\
1,131 / 17.2\end{array}$ & $\begin{array}{l}166 / 25.5 \\
149 / 22.9\end{array}$ & \\
\hline Age at diagnosis, years (mean (SD)) & $71.4(12.1)$ & $73.7(8.6)$ & $<0.001$ \\
\hline Follow-up time, years (median (interquartile range)) ${ }^{\mathrm{b}}$ & $3.3(5.4)$ & $3.0(4.5)$ & 0.042 \\
\hline \multicolumn{4}{|l|}{ Dukes' stage at diagnosis $(n / \%$ of total $)$} \\
\hline Stage A & $651 / 9.9$ & $52 / 8.0$ & \\
\hline Stage B & $2,268 / 34.5$ & $262 / 40.3$ & 0.006 \\
\hline
\end{tabular}


Table 1 (continued)

\begin{tabular}{lll}
\hline Characteristic & $\begin{array}{l}\text { No T2DM at diagnosis } \\
\text { of colon cancer }\end{array}$ & $\begin{array}{l}\text { T2DM at diagnosis } \\
\text { of colon cancer }\end{array}$ \\
\hline $\begin{array}{l}\text { Stage C } \\
\text { Stage D }\end{array}$ & $2,069 / 31.5$ & $207 / 31.8$ \\
Surgery $(n / \%$ of total) & $1,586 / 24.1$ & $129 / 19.8$ \\
No & & \\
Yes & $726 / 11.0$ & $72 / 11.1$ \\
Unknown/missing & $5,813 / 88.4$ & $577 / 88.8$ \\
Chemotherapy $(n / \%$ of total) & $35 / 0.5$ & $1 / 0.2$ \\
No & & $484 / 74.5$ \\
Yes & $4,318 / 65.7$ & $134 / 20.6$ \\
Unknown/missing & $1,961 / 29.8$ & $32 / 4.9$ \\
\hline
\end{tabular}

${ }^{a}$ For survival status, SIMD quintile and cancer stage, the $p$ value is that obtained from a $\chi^{2}$ test. For individual treatment regimens (e.g. surgery), $p$ value indicates result of Fisher's exact test (applied to non-missing values [No/Yes] only). For age at diagnosis, $p$ value is that returned by a twosample $t$ test (Satterthwaite's approximation used where equality of group variances is questionable). For follow-up time, the $p$ value is derived from a Mann-Whitney test

${ }^{\mathrm{b}}$ Time shown is that until either death or censoring

T2DM, type 2 diabetes mellitus

Table 2 presents estimated HRs representing the effect of comorbid type 2 diabetes on overall survival in patients with colon cancer within each time period. Estimates are given for all models in the series, increasing in complexity from one including only age and diabetes status as predictors through successively fuller models. The sequential addition of SES and subsequently of cancer stage resulted in relatively little change to estimates (relative to a model adjusted for age only). In men, pre-existing diabetes was associated with significantly poorer survival (increased HR) in the period beyond 5 years after diagnosis, and with a marginally significant survival deficit in the interval $>2-5$ years after diagnosis. Broadly similar effects were observed in women with colon cancer. For both sexes, inclusion of the treatment variables had little effect on the estimated influence of diabetes. As explained above, complete treatment data were available for only a subset of patients; people with and without nonmissing treatment data are compared (for both cancer sites) in electronic supplementary material (ESM) Table 1. A sensitivity analysis based on exclusion of patients with metastatic colon cancer (ESM Table 2) did not materially affect the HR estimates.

Table 2 HRs representing association between presence of type 2 diabetes and all-cause mortality stratified by length of follow-up: people diagnosed with colon cancer in Scotland during the period 2000-2007

\begin{tabular}{llllll}
\hline Sex & Model adjusted for & $\begin{array}{l}\text { HR }(95 \% \mathrm{CI}): \\
0-1 \text { year }^{\mathrm{a}}\end{array}$ & $\begin{array}{l}\text { HR (95\% CI): } \\
>1-2 \text { years }^{\mathrm{b}}\end{array}$ & $\begin{array}{c}\text { HR }(95 \% \mathrm{CI}): \\
>2-5 \text { years }^{\mathrm{c}}\end{array}$ & $\begin{array}{c}\text { HR }(95 \% \mathrm{CI}): \\
>5 \text { years }^{\mathrm{d}}\end{array}$ \\
\hline Men $(n=7,474)$ & Age (at cancer diagnosis) & $1.03(0.90,1.17)$ & $0.91(0.74,1.12)$ & $1.18(1.00,1.39)$ & $1.58(1.20,2.08)$ \\
& Age, SES & $1.00(0.88,1.14)$ & $0.90(0.73,1.09)$ & $1.16(0.98,1.36)$ & $1.56(1.19,2.06)$ \\
& Age, SES, stage & $1.01(0.89,1.15)$ & $0.87(0.71,1.07)$ & $1.13(0.96,1.34)$ & $1.57(1.19,2.06)$ \\
& As above + treatment ${ }^{\mathrm{e}}(n=7,099)$ & $0.98(0.86,1.13)$ & $0.88(0.71,1.08)$ & $1.12(0.94,1.33)$ & $1.43(1.08,1.91)$ \\
Women $(n=7,224)$ & Age (at cancer diagnosis) & $0.94(0.81,1.10)$ & $1.09(0.87,1.36)$ & $1.23(1.01,1.50)$ & $1.70(1.25,2.30)$ \\
& Age, SES & $0.92(0.79,1.07)$ & $1.06(0.85,1.32)$ & $1.20(0.98,1.46)$ & $1.66(1.22,2.24)$ \\
& Age, SES, stage & $0.98(0.84,1.14)$ & $1.16(0.92,1.45)$ & $1.27(1.04,1.55)$ & $1.84(1.36,2.50)$ \\
& As above + treatment $^{\mathrm{e}}(n=6,888)$ & $0.91(0.78,1.07)$ & $1.13(0.90,1.42)$ & $1.29(1.05,1.58)$ & $1.92(1.42,2.60)$ \\
\hline
\end{tabular}

\footnotetext{
${ }^{\mathrm{a}} \mathrm{HR}$ in period 0-365 days after diagnosis with cancer

${ }^{\mathrm{b}} \mathrm{HR}$ in period $>1-2$ years after diagnosis with cancer

${ }^{\mathrm{c}} \mathrm{HR}$ in period $>2-5$ years after diagnosis with cancer

${ }^{\mathrm{d}} \mathrm{HR}$ in period $>5$ years after diagnosis with cancer

${ }^{\mathrm{e}}$ Treatment represented by binary indicators marking receipt of surgery (Yes/No) and chemotherapy (Yes/No)
} 
Table 3 Characteristics of people with rectal cancer included in study, by sex and diabetes status

\begin{tabular}{|c|c|c|c|}
\hline Characteristic & No T2DM at diagnosis of rectal cancer & $\mathrm{T} 2 \mathrm{DM}$ at diagnosis of rectal cancer & $p$ value $^{\mathrm{a}}$ \\
\hline \multicolumn{4}{|l|}{ Men } \\
\hline Patients/deaths & $2,647 / 1,484$ & $296 / 178$ & \\
\hline \multicolumn{4}{|l|}{ Survival status at study end ( $n / \%$ of total $)$} \\
\hline $\begin{array}{l}\text { Still alive } \\
\text { Dead, colon cancer }\end{array}$ & $\begin{array}{l}1,163 / 43.9 \\
322 / 12.2\end{array}$ & $\begin{array}{l}118 / 39.9 \\
29 / 9.8\end{array}$ & \\
\hline Dead, rectal cancer & $714 / 27.0$ & $81 / 27.4$ & \multirow[t]{3}{*}{0.016} \\
\hline $\begin{array}{l}\text { Dead, CVD } \\
\text { Dead, other cancers }\end{array}$ & $\begin{array}{l}117 / 4.4 \\
180 / 6.8\end{array}$ & $\begin{array}{l}23 / 7.8 \\
18 / 6.1\end{array}$ & \\
\hline Dead, other causes & $151 / 5.7$ & $27 / 9.1$ & \\
\hline \multicolumn{4}{|l|}{ SIMD quintile ( $n / \%$ of total $)$} \\
\hline $\begin{array}{l}\text { Q1 (least deprived) } \\
\text { Q2 }\end{array}$ & $\begin{array}{l}502 / 19.0 \\
495 / 18.7\end{array}$ & $\begin{array}{l}47 / 15.9 \\
49 / 16.6\end{array}$ & \\
\hline Q3 & $575 / 21.7$ & $62 / 20.9$ & \multirow[t]{2}{*}{0.095} \\
\hline $\begin{array}{l}\text { Q4 } \\
\text { Q5 (most deprived) }\end{array}$ & $\begin{array}{l}592 / 22.4 \\
483 / 18.2\end{array}$ & $\begin{array}{l}65 / 22.0 \\
73 / 24.7\end{array}$ & \\
\hline Age at diagnosis, years (mean (SD)) & $67.0(10.9)$ & $69.7(8.8)$ & $<0.001$ \\
\hline Follow-up time, years (median (interquartile range)) ${ }^{\mathrm{b}}$ & $3.7(4.8)$ & $3.4(4.1)$ & 0.033 \\
\hline \multicolumn{4}{|l|}{ Dukes' stage at diagnosis $(n / \%$ of total $)$} \\
\hline Stage A & $582 / 22.0$ & $73 / 24.7$ & \multirow{3}{*}{0.602} \\
\hline Stage B & $681 / 25.7$ & $79 / 26.7$ & \\
\hline $\begin{array}{l}\text { Stage C } \\
\text { Stage D }\end{array}$ & $\begin{array}{l}797 / 30.1 \\
587 / 22.2\end{array}$ & $\begin{array}{l}86 / 29.1 \\
58 / 19.6\end{array}$ & \\
\hline \multicolumn{4}{|l|}{ Surgery $(n / \%$ of total $)$} \\
\hline No & $327 / 12.4$ & $37 / 12.5$ & \multirow{3}{*}{0.926} \\
\hline Yes & $2,308 / 87.2$ & $256 / 86.5$ & \\
\hline Unknown/missing & $12 / 0.5$ & $3 / 1.0$ & \\
\hline \multicolumn{4}{|l|}{ Radiotherapy ( $n / \%$ of total) } \\
\hline No & $1,595 / 60.3$ & $191 / 64.5$ & \multirow{3}{*}{0.207} \\
\hline Yes & $867 / 32.8$ & $87 / 29.4$ & \\
\hline Unknown/missing & $185 / 7.0$ & $18 / 6.1$ & \\
\hline \multicolumn{4}{|l|}{ Chemotherapy ( $n / \%$ of total) } \\
\hline No & $1,386 / 52.4$ & $180 / 60.8$ & \multirow{3}{*}{0.006} \\
\hline Yes & $1,157 / 43.7$ & $105 / 35.5$ & \\
\hline Unknown/missing & $104 / 3.9$ & $11 / 3.7$ & \\
\hline \multicolumn{4}{|l|}{ Women } \\
\hline Patients/deaths & $1,730 / 881$ & $134 / 68$ & \\
\hline \multicolumn{4}{|l|}{ Survival status at study end ( $n / \%$ of total $)$} \\
\hline $\begin{array}{l}\text { Still alive } \\
\text { Dead, colon cancer }\end{array}$ & $\begin{array}{l}849 / 49.1 \\
173 / 10.0\end{array}$ & $\begin{array}{l}66 / 49.3 \\
14 / 10.4\end{array}$ & \multirow{4}{*}{0.022} \\
\hline Dead, rectal cancer & $431 / 24.9$ & $25 / 18.7$ & \\
\hline $\begin{array}{l}\text { Dead, CVD } \\
\text { Dead, other cancers }\end{array}$ & $\begin{array}{l}77 / 4.5 \\
127 / 7.3\end{array}$ & $\begin{array}{l}12 / 9.0 \\
6 / 4.5\end{array}$ & \\
\hline Dead, other causes & $73 / 4.2$ & $11 / 8.2$ & \\
\hline \multicolumn{4}{|l|}{ SIMD quintile ( $n / \%$ of total $)$} \\
\hline $\begin{array}{l}\text { Q1 (least deprived) } \\
\text { Q2 }\end{array}$ & $\begin{array}{l}331 / 19.1 \\
346 / 20.0\end{array}$ & $\begin{array}{l}18 / 13.4 \\
27 / 20.1\end{array}$ & \multirow{3}{*}{0.239} \\
\hline Q3 & $360 / 20.8$ & $27 / 20.1$ & \\
\hline $\begin{array}{l}\text { Q4 } \\
\text { Q5 (most deprived) }\end{array}$ & $\begin{array}{l}387 / 22.4 \\
306 / 17.7\end{array}$ & $\begin{array}{l}29 / 21.6 \\
33 / 24.6\end{array}$ & \\
\hline Age at diagnosis, years (mean (SD)) & $68.2(12.2)$ & $72.1(9.1)$ & $<0.001$ \\
\hline
\end{tabular}


Table 3 (continued)

\begin{tabular}{|c|c|c|c|}
\hline Characteristic & No T2DM at diagnosis of rectal cancer & $\mathrm{T} 2 \mathrm{DM}$ at diagnosis of rectal cancer & $p$ value $^{\mathrm{a}}$ \\
\hline Follow-up time, years (median (interquartile range)) ${ }^{\mathrm{b}}$ & $4.0(5.3)$ & $3.7(4.4)$ & 0.184 \\
\hline \multicolumn{4}{|l|}{ Dukes' stage at diagnosis ( $n / \%$ of total) } \\
\hline Stage A & $405 / 23.4$ & $32 / 23.9$ & \\
\hline Stage B & $483 / 27.9$ & $39 / 29.1$ & 0.540 \\
\hline Stage C & $497 / 28.7$ & $43 / 32.1$ & \\
\hline Stage D & $345 / 19.9$ & 20/14.9 & \\
\hline \multicolumn{4}{|l|}{ Surgery $(n / \%$ of total $)$} \\
\hline No & $175 / 10.1$ & $10 / 7.5$ & \\
\hline Yes & $1,542 / 89.1$ & $123 / 91.8$ & 0.371 \\
\hline Unknown/missing & $13 / 0.8$ & $1 / 0.7$ & \\
\hline \multicolumn{4}{|l|}{ Radiotherapy ( $n / \%$ of total) } \\
\hline No & $1,173 / 67.8$ & $88 / 65.7$ & \\
\hline Yes & $460 / 26.6$ & $33 / 24.6$ & 0.917 \\
\hline Unknown/missing & $97 / 5.6$ & $13 / 9.7$ & \\
\hline \multicolumn{4}{|l|}{ Chemotherapy ( $n / \%$ of total) } \\
\hline No & $1,043 / 60.3$ & $91 / 67.9$ & \\
\hline Yes & $610 / 35.3$ & $32 / 23.9$ & 0.015 \\
\hline Unknown/missing & $77 / 4.5$ & $11 / 8.2$ & \\
\hline
\end{tabular}

${ }^{\text {a }}$ For survival status, SIMD quintile and cancer stage, the $p$ value is that obtained from a $\chi^{2}$ test. For individual treatment regimens (e.g. surgery), $p$ value indicates result of Fisher's exact test (applied to non-missing values [No/Yes] only). For age at diagnosis, $p$ value is that returned by a twosample $t$ test (Satterthwaite's approximation used where equality of group variances is questionable). For follow-up time, the $p$ value is derived from a Mann-Whitney test

${ }^{\mathrm{b}}$ Time shown is that until either death or censoring

T2DM, type 2 diabetes mellitus

Table 3 presents summary characteristics for patients with rectal cancer. In people with rectal cancer, CRC was again the most common cause of death for both sexes and both diabetes groups, and the proportions of deaths from CVD were again higher in those with pre-existing diabetes. Differences in the distribution of SES and in age at cancer

Table 4 HRs representing association between presence of type 2 diabetes and all-cause mortality stratified by length of follow-up: people diagnosed with rectal cancer in Scotland during the period 2000-2007

\begin{tabular}{|c|c|c|c|c|c|}
\hline Sex & Model adjusted for & $\begin{array}{l}\text { HR (95\% CI): 0-1 } \\
\text { year }^{\text {a }}\end{array}$ & $\begin{array}{l}\text { HR }(95 \% \text { CI }):>1-2 \\
\text { years }{ }^{b}\end{array}$ & $\begin{array}{l}\text { HR }(95 \% \mathrm{CI}):>2-5 \\
\text { years }^{\mathrm{c}}\end{array}$ & $\begin{array}{l}\text { HR }(95 \% \mathrm{CI}):>5 \\
\text { years }^{\mathrm{d}}\end{array}$ \\
\hline \multirow[t]{4}{*}{$\operatorname{Men}(n=2,943)$} & Age (at cancer diagnosis) & $1.01(0.77,1.34)$ & $0.99(0.72,1.38)$ & $1.19(0.92,1.55)$ & $1.27(0.78,2.06)$ \\
\hline & Age, SES & $0.99(0.75,1.30)$ & $0.96(0.69,1.33)$ & $1.15(0.88,1.49)$ & $1.22(0.75,1.99)$ \\
\hline & Age, SES, stage & $1.10(0.84,1.46)$ & $1.01(0.73,1.40)$ & $1.10(0.85,1.43)$ & $1.01(0.62,1.64)$ \\
\hline & $\begin{array}{l}\text { As above }+ \text { treatment }^{\mathrm{e}} \\
\quad(n=2,725)\end{array}$ & $1.09(0.82,1.45)$ & $0.96(0.68,1.34)$ & $1.05(0.79,1.39)$ & $1.00(0.62,1.64)$ \\
\hline \multirow{4}{*}{$\begin{array}{l}\text { Women } \\
\qquad(n=1,864)\end{array}$} & Age (at cancer diagnosis) & $0.92(0.61,1.39)$ & $1.02(0.62,1.67)$ & $0.83(0.52,1.34)$ & $1.20(0.61,2.36)$ \\
\hline & Age, SES & $0.91(0.60,1.38)$ & $1.00(0.61,1.64)$ & $0.82(0.51,1.32)$ & $1.15(0.58,2.26)$ \\
\hline & Age, SES, stage & $1.03(0.68,1.57)$ & $1.05(0.64,1.72)$ & $0.88(0.54,1.42)$ & $1.45(0.73,2.86)$ \\
\hline & $\begin{array}{l}\text { As above }+ \text { treatment }^{\mathrm{e}} \\
\quad(n=1,737)\end{array}$ & $1.08(0.71,1.66)$ & $0.93(0.54,1.60)$ & $0.92(0.55,1.53)$ & $1.27(0.59,2.73)$ \\
\hline
\end{tabular}

${ }^{\mathrm{a}} \mathrm{HR}$ in period $0-365$ days after diagnosis with cancer

${ }^{\mathrm{b}} \mathrm{HR}$ in period $>1-2$ years after diagnosis with cancer

${ }^{\mathrm{c}} \mathrm{HR}$ in period $>2-5$ years after diagnosis with cancer

${ }^{\mathrm{d}} \mathrm{HR}$ in period $>5$ years after diagnosis with cancer

${ }^{\mathrm{e}}$ Treatment represented by binary indicators marking receipt of surgery (Yes/No), radiotherapy (Yes/No) and chemotherapy (Yes/No) 
diagnosis by diabetes status were evident, those with type 2 diabetes being more deprived and older. As was observed for colon cancer, receipt of chemotherapy was less prevalent in people with type 2 diabetes. Table 4 gives HRs representing the effect of pre-existing type 2 diabetes on survival in patients with cancer of the rectum. Pre-existing diabetes was generally not associated with significantly altered mortality risk for either sex in any time period. As for cancer of the colon, the estimated influence of diabetes on survival was little affected by the introduction of the treatment variables or by the exclusion of individuals with metastatic cancer (ESM Table 3).

CIFs for cause-specific death are shown in Fig. 1a-d (men, colon cancer) and Fig. 2a-d (women, colon cancer). Corresponding figures for men and women with rectal cancer exhibit similar patterns (ESM Figs $1 \mathrm{a}-\mathrm{d}$ and $2 \mathrm{a}-\mathrm{d}$ ). The results from Gray's tests of homogeneity of CIFs (Table 5) indicated that, for both sites and both sexes, pre-existing type 2 diabetes was associated with a highly significant $(p<0.01)$ difference in the cumulative incidence of death from CVD, and a significant or marginally significant difference in the cumulative incidence of death from other causes (non-cancer, non-CVD; $p$ values ranging from $<0.01$ to 0.06 ). The figures indicate that, for CVD and other causes of death (non-CVD, non-cancer), type 2 diabetes is associated with a poorer survival experience. For death from colorectal cancer and from
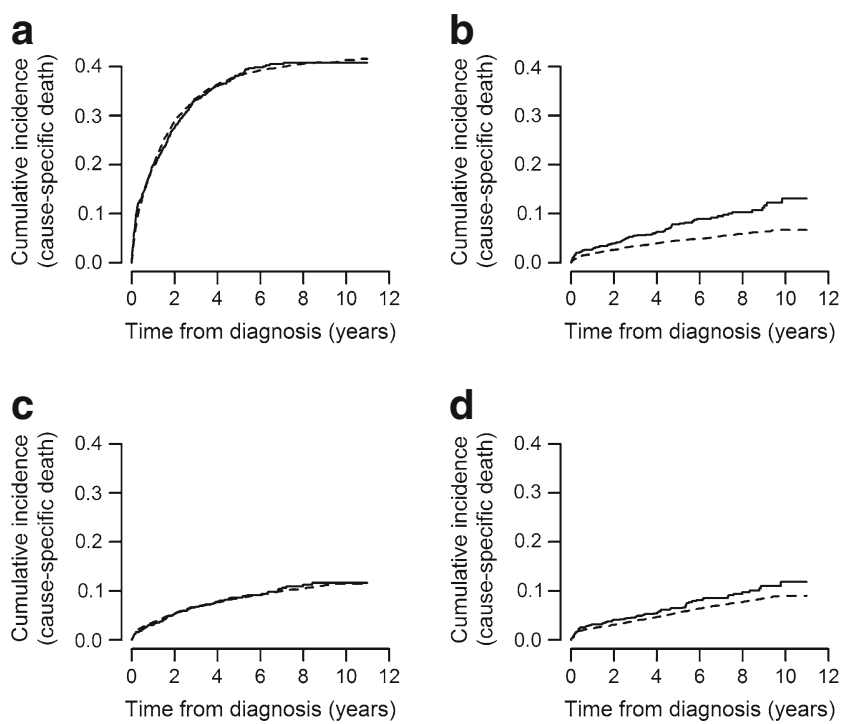

\begin{tabular}{lcccccc} 
Group & \multicolumn{5}{c}{ Number at risk at time from diagnosis of cancer } \\
& 0 years & 2 years & 4 years & 6 years & 8 years & 10 years \\
\hline No diabetes & 6,597 & 3,962 & 2,693 & 1,647 & 899 & 250 \\
T2DM & 877 & 518 & 315 & 162 & 82 & 24
\end{tabular}

Fig. 1 CIFs representing probabilities of death in men with colon cancer from (a) CRC, (b) CVD, (c) other cancers and (d) any other cause. Solid line, type 2 diabetes group; dashed line, group with no diabetes; T2DM, type 2 diabetes mellitus a

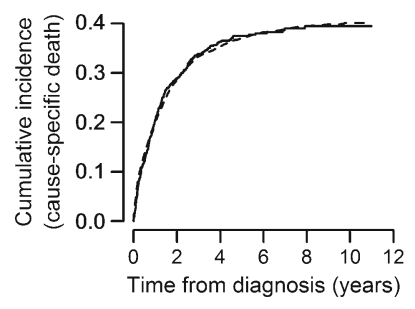

C

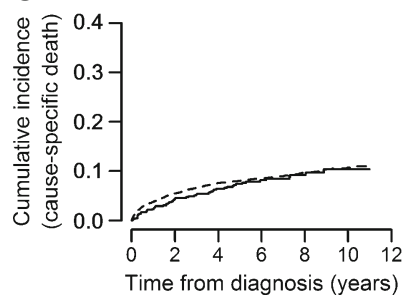

b

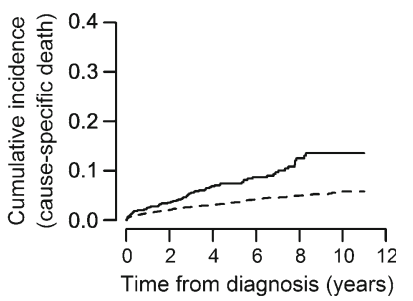

d

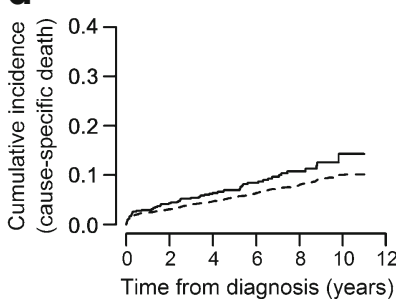

\begin{tabular}{lcccccc} 
Group & \multicolumn{5}{c}{ Number at risk at time from diagnosis of cancer } \\
& 0 years & 2 years & 4 years & 6 years & 8 years & 10 years \\
& & & & & & \\
\hline No diabetes & 6,574 & 3,984 & 2,775 & 1,739 & 976 & 285 \\
T2DM & 650 & 382 & 246 & 130 & 59 & 11 \\
\hline
\end{tabular}

Fig. 2 CIFs representing probabilities of death in women with colon cancer from (a) CRC, (b) CVD, (c) other cancers and (d) any other cause. Solid line, type 2 diabetes group; dashed line, group with no diabetes; T2DM, type 2 diabetes mellitus

other cancers, there is insufficient evidence from these data to conclude that the cumulative incidence of death from CRC or from other cancers differs between diabetes groups.

\section{Discussion}

This study extends current knowledge of the previously observed excess risk of all-cause mortality in patients with CRC who have pre-existing type 2 diabetes in two respects. First, we have assessed the effect of type 2 diabetes on overall survival in people with cancer of the colon or rectum over multiple discrete time periods after cancer diagnosis. This is in contrast with many previous investigations in this area, which have mostly calculated single estimates of cumulative relative risk over the follow-up period. Consequently, these investigations have been restricted in their ability to determine how the influence of diabetes on survival behaves over time. Second, we have examined the influence of type 2 diabetes on cause-specific mortality using a wider range of mortality outcomes than has generally been represented in previous studies. Hitherto, investigations assessing the impact of diabetes on survival in people with CRC have generally considered cancerspecific mortality and either overall mortality or mortality from all causes except CRC [8, 10, 11, 13]. This 
Table 5 Results from Gray's tests for homogeneity of CIFs

The values in parentheses are absolute number of deaths from the specified cause in no-diabetes group/absolute number of deaths in type 2 diabetes group. The null hypothesis assessed is that the cumulative incidence of death from cause $X$ is identical across the two diabetes groups; small $p$ values are interpreted as evidence that the CIFs differ between diabetes groups

T2DM, type 2 diabetes mellitus

\begin{tabular}{|c|c|c|c|c|}
\hline \multirow[t]{3}{*}{ Cause of death } & \multicolumn{4}{|c|}{$p$ value (deaths, no diabetes/deaths, T2DM) } \\
\hline & \multicolumn{2}{|l|}{ Men } & \multicolumn{2}{|l|}{ Women } \\
\hline & Colon & Rectum & Colon & Rectum \\
\hline \multirow[t]{2}{*}{$\mathrm{CRC}$} & 0.992 & 0.637 & 0.982 & 0.231 \\
\hline & $(2,588 / 341)$ & $(1,036 / 110)$ & $(2,509 / 247)$ & $(604 / 39)$ \\
\hline \multirow[t]{2}{*}{ CVD } & $<0.001$ & 0.005 & $<0.001$ & 0.007 \\
\hline & $(352 / 80)$ & $(117 / 23)$ & $(293 / 64)$ & $(77 / 12)$ \\
\hline \multirow[t]{2}{*}{ Other cancers } & 0.817 & 0.800 & 0.577 & 0.261 \\
\hline & $(639 / 85)$ & $(180 / 18)$ & $(595 / 54)$ & $(127 / 6)$ \\
\hline \multirow[t]{2}{*}{ Other } & 0.064 & 0.007 & 0.022 & 0.011 \\
\hline & $(457 / 73)$ & $(151 / 27)$ & $(477 / 61)$ & $(73 / 11)$ \\
\hline
\end{tabular}

concentration on a limited range of mortality outcomes is a limitation of previous research, which is highlighted in the 'framework' paper of Renehan et al [14]. One notable exception [12] examined all-cause mortality, CRC-specific mortality and death from CVD. However, the authors of that study acknowledged that it was limited by the self-reported nature of patients' type 2 diabetes status. To our knowledge, the four-way cause-of-death classification used in the present study has not featured before in any study examining the influence of diabetes on survival in patients with CRC.

We observed a significant overall survival deficit associated with type 2 diabetes in people with cancer of the colon more than 5 years after cancer diagnosis, and a marginally significant elevation of hazard in the period $>2-5$ years after diagnosis. In the case of rectal cancer, we found no significant effect of diabetes in any time interval. The latter finding differs from that of a recent study in the Netherlands [13], which found an increased risk of all-cause mortality in diabetic patients with cancer of either colon or rectum. However, our findings with respect to overall survival are not directly comparable with those obtained in earlier studies because of our approach of estimating the effect of diabetes separately for multiple time periods (although there may also be true differences between populations which would require further investigation).

Turning to cause-specific mortality, the limited earlier work assessing the effect of diabetes on survival when death from CRC itself is defined as the endpoint has produced mixed results. One study that was restricted to cancer of the colon [11] observed a significant detrimental effect of diabetes on colon cancer-specific survival. A second investigation (which combined cancers of the colon and rectum) found a marginally significant influence of diabetes on CRC-specific survival [12], while the Dutch study that treated the two sites separately found that diabetes at the time of cancer diagnosis was associated with an increased risk of CRC mortality in people with cancer of the rectum but not of the colon [13]. Two further studies [8, 10] detected no significant effect, but one of these [10] was based on only about 1,200 patients (97 with comorbid diabetes) and thus possibly had limited power to detect modest effects. Results from the present study accord with those from the two latter investigations: examination of the CIFs and formal testing suggest that the probability of CRC death (the dominant cause of death in this population) in people with cancer of either the colon or rectum is largely unrelated to pre-existing type 2 diabetes at the point of cancer diagnosis. For CVD-specific mortality, the only study to consider this outcome [12] found that type 2 diabetes was linked to an approximately twofold increase in risk of CVD-specific mortality. This investigation combined cancers of the colon and rectum. The CIFs generated in the present study are consistent with elevated CVD death risk among people with type 2 diabetes and cancer at either site, which increases over time compared with a population with these cancers but not type 2 diabetes. However, we found that other causes of death (non-CVD and non-cancer) also contribute to the poorer overall survival observed in patients with CRC who have pre-existing type 2 diabetes.

One strength of the present study is its use of wholepopulation data rather than selected subgroups, e.g. hospital patients. Apart from providing a large sample, this eliminates a number of sources of potential bias. A second strength is availability of a reliable marker of diabetes status: SCI-DC provides a good indication of whether a cancer patient has clinically diagnosed diabetes. One further positive feature of the investigation is the adoption as an outcome of CIFs (which explicitly recognise the competing risks present when multiple, mutually exclusive endpoints are of interest).

We acknowledge a number of potential weaknesses in this study. Although secular trends in treatment may have occurred during the 8-year study period, the reported stability of survival of people with CRC in Scotland over the time 
interval 1998-2007 suggests that this is unlikely to have an important effect [22]. The violation of proportional hazards reported in this investigation (for colon cancer patients only) is rarely reported in studies of diabetes and cancer survival. This may reflect the effect of unobserved covariates rather than 'true' non-proportionality. The study of Dehal and colleagues [12] incorporated a number of plausible predictors (e.g. body mass index, intake of red meat) that were not available for this analysis, which may mean that our findings are subject to residual confounding. More generally, a complete model would ideally include additional predictors such as comorbidities in addition to diabetes status and tumour stage.

The representation of cancer treatments used in this study (binary indicators of major treatment lines) is crude, and unable to capture treatment regimens such as preoperative administration of chemoradiotherapy in the treatment of $\mathrm{T} 4$ tumours. While clearly undesirable, this stems from fundamental limitations of the data available to us. In the same vein, a body of evidence suggests that treatments for diabetes have the potential to influence cancer risk, so, although examination of these effects was beyond the scope of this paper, this topic is worthy of future research.

A further possible limitation is that cause of death in the study was derived solely from the main or underlying cause recorded on death certification. This potentially affects classification of CVD deaths. Where both diabetes and CVD appear on a death certificate, international coding rules stipulate that the former should be specified as the underlying cause of death [18]. However, the number of patients with type 2 diabetes for whom the underlying cause of death is diabetes, and CVD appears as a secondary cause, is small (six of 73 'other-cause' deaths in men with type 2 diabetes and colon cancer; four of 27 deaths in men with rectal cancer; six of 61 deaths in women with colon cancer; and one of 11 deaths in women with rectal cancer). Consequently, this aspect of death coding practice is unlikely to have materially affected our findings with respect to cause-specific mortality.

In summary, this study was conducted on a considerably larger scale than previous investigations assessing links between diabetes and CRC-specific and CVD-specific survival. We found that pre-existing diabetes exerts little influence on CRC death, which accords with earlier findings [8, 10]. In addition, people who have type 2 diabetes at the point when cancer of the colon or rectum is detected experience poorer survival with respect to death from CVD than those who do not have type 2 diabetes at diagnosis of cancer. This specific detrimental influence of type 2 diabetes may partly explain the poorer overall survival that has been repeatedly observed in patients with CRC who have diabetes. However, our findings also indicate that the excess risk of death from other causes (non-cancer, non-CVD) contributes to the influence of type 2 diabetes on overall survival.
Acknowledgements This work is presented by the named authors on behalf of all members of the Scottish Diabetes Research Network Epidemiology Group. The data used are available for analysis thanks to the hard work of numerous NHS staff who enter the data and people and organisations (the SCI-DC Steering Group, the Scottish Diabetes Group, the Scottish Diabetes Survey Monitoring Group, the managed clinical network managers and staff in each Health Board) involved in setting up, maintaining and overseeing SCI-DC. Thanks are due also to staff of the Scottish Cancer Registry and to the ISD record linkage team.

Funding This work was funded by the European Foundation for the Study of Diabetes (grant number 90768) and the Wellcome Trust through the Scottish Health Informatics Programme (SHIP) Grant (grant number WT086113). Funding for diabetes register linkage was provided by the Scottish Government, and the authors acknowledge the financial support of NHS Research Scotland, through the Scottish Diabetes Research Network.

Duality of interest The authors declare that there is no duality of interest associated with this manuscript.

Contribution statement JJW conducted the main data analysis and contributed to drafting of the manuscript. DHB and CMF contributed to interpretation of the data and critical revision of the text. RSL made contributions to the acquisition of data and revision of the manuscript. HMC contributed to the acquisition and interpretation of data, and to critical revision of the text. SHW designed the study, and contributed to acquisition and interpretation of data, and drafting and revising the article. All authors approved the final version of the text.

\section{References}

1. Larsson SC, Orsini N, Wolk A (2005) Diabetes mellitus and risk of colorectal cancer: a meta-analysis. J Natl Canc Inst 97:1679-1687

2. Deng L, Gui Z, Zhao L, Wang J, Shen L (2012) Diabetes mellitus and the incidence of colorectal cancer: an updated systematic review and meta-analysis. Dig Dis Sci 57:1576-1585

3. Sun L, Yu S (2012) Diabetes mellitus is an independent risk factor for colorectal cancer. Dig Dis Sci 57:1586-1597

4. Erbach M, Mehnert H, Schnell O (2012) Diabetes and the risk for colorectal cancer. J Diabetes Complications 26:50-55

5. Yancik R, Wesley MN, Ries LAG et al (1998) Comorbidity and age as predictors of risk for early mortality of male and female colon carcinoma patients. Cancer 82:2123-2134

6. Meyerhardt JA, Catalano PJ, Haller DG et al (2003) Impact of diabetes mellitus on outcomes in patients with colon cancer. J Clin Oncol 21:433-440

7. Gross CP, Guo Z, McAvay GJ, Allore HG, Young M, Tinetti ME (2006) Multimorbidity and survival in older persons with colorectal cancer. J Am Geriatr Soc 54:1898-1904

8. Polednak AP (2006) Comorbid diabetes mellitus and risk of death after diagnosis of colorectal cancer: a population-based study. Canc Detect Prev 30:466-472

9. van de Poll-Franse LV, Houterman S, Janssen-Heijnen MLG, Dercksen MW, Coebergh JWW, Haak HR (2007) Less aggressive treatment and worse overall survival in cancer patients with diabetes: a large population based analysis. Int J Cancer 120:19861992

10. Jullumstro E, Kollind M, Lydersen S, Edna T-H (2009) Diabetes mellitus and outcomes of colorectal cancer. Acta Oncol 48:361367 
11. Huang Y-C, Lin J-K, Chen W-S et al (2011) Diabetes mellitus negatively impacts survival of patients with colon cancer, particularly in stage II disease. J Cancer Res Clin Oncol 137:211-220

12. Dehal AN, Newton CC, Jacobs EJ, Patel AV, Gapstur SM, Campbell PT (2012) Impact of diabetes mellitus and insulin use on survival after colorectal cancer diagnosis: The Cancer Prevention Study-II Nutrition Cohort. J Clin Oncol 30:53-59

13. van de Poll-Franse LV, Haak HR, Coebergh JWW, JanssenHeijnen MLG, Lemmens VEPP (2012) Disease-specific mortality among stage I-III colorectal cancer patients with diabetes: a large population-based analysis. Diabetologia 55:2163-2172

14. Renehan AG, Yeh H-C, Johnson JA, Wild SH, Gale EAM, Moller $\mathrm{H}$ (2012) Diabetes and cancer (2): evaluating the impact of diabetes on mortality in patients with cancer. Diabetologia 55:16191632

15. Brewster DH, Stockton D, Harvey J, Mackay M (2002) Reliability of cancer registration data in Scotland, 1997. Eur J Cancer 38:414 417

16. Scottish Executive, Office of the Chief Statistician (2006) Scottish index of multiple deprivation 2006: technical report. Available from www.scotland.gov.uk/Resource/Doc/933/0041180.pdf, (accessed 19th March 2013)

17. McKnight JA, Morris AD, Clinet D, Peden N, Fischbacher C, Wild S (2008) Implementing a national quality assurance system for diabetes care: the Scottish Diabetes Survey 2001-2006. Diabet Med 25:743-746

18. World Health Organization (2010) International statistical classification of diseases and related health problems (10th revision). Volume 2 (instruction manual) (2010). World Health Organization, Geneva

19. Pintilie M (2006) Competing risks: a practical perspective. Wiley, Chichester

20. Putter H, Fiocco M, Geskus RB (2007) Tutorial in biostatistics: competing risks and multi-state models. Stat Med 26:2389-2430

21. Gray RT (1998) A class of K-sample tests for comparing the cumulative incidence of a competing risk. Ann Stat 16:1141-1154

22. Information Services Division, National Services Scotland (2010) Trends in cancer survival in Scotland, 1983-2007. Available from www.isdscotland.org/Health-Topics/Cancer/Cancer-Statistics/ Survival_summary_8307.pdf?1, (accessed 19th March 2013) 